Re-submitted to Neuropsychologia, September 2009

Research Report

Senior Editor

\title{
EEG activations during intentional inhibition of voluntary action: an electrophysiological correlate of self-control?
}

\section{Shortened Title: A neural correlate of self-control?}

E. Walsh ${ }^{\text {a }}$, S. Kühn ${ }^{\text {b,c }}$, M. Brass ${ }^{\mathrm{b}}$, D. Wenke ${ }^{\mathrm{c}}$, P. Haggard ${ }^{\mathrm{a}, *}$,

*Corresponding author: P. Haggard

${ }^{\mathrm{a}}$ Institute of Cognitive Neuroscience

Department of Psychology, University College London

17 Queen Square, London. WC1N 3AR. United Kingdom

Phone: 44 (0)20 76791177

Fax: 44 (0)20 78132835

Email: p.haggard@ucl.ac.uk

URL: http://www.icn.ucl.ac.uk/research-groups/Motor-Control-Group/index.php

${ }^{\mathrm{b}}$ Department of Experimental Psychology

Ghent University

Henri Dunantlaan 2

9000 Ghent, Belgium

${ }^{\mathrm{c}}$ Department of Psychology

Max Planck Institute for Human Cognitive and Brain Sciences

Stephanstraße 1A, 04103 Leipzig, Germany

Number of text pages: 23

Number of Figures and Tables: 4 units

Word-count: 6210 words 


\begin{abstract}
An important aspect of volition is the internal decision whether to act or to withhold an action. We used EEG frequency analysis of sensorimotor rhythms to investigate brain activity when people prepare and then cancel a voluntary action. Participants used a rotating clock-hand to report when they experienced the intention to press a key with their right hand, even on trials where they freely decided to inhibit movement at the last moment. On action trials, we observed the classical pattern of reduced beta-band spectral power prior to movement, followed by beta rebound after movement. On inhibition trials where participants prepared but then cancelled a movement, we found a left frontal increase in spectral power (event-related synchronization: ERS) peaking $12 \mathrm{~ms}$ before the perceived intention to move. This neural correlate of intentional inhibition was significantly different from the activity at the corresponding moment in action trials. The results are discussed in the context of a recent model of voluntary action (WWW model; Brass and Haggard, 2008). Planned actions can be subjected to a final predictive check which either commits actions for execution or suspends and withholds them. The neural mechanism of intentional inhibition may play an important role in self-control.
\end{abstract}

Keywords: Intentional action, motor control, response inhibition; electroencephalography (EEG); event-related desynchronization (ERD); event-related synchronization (ERS).

\title{
1. Introduction
}

The ability to make voluntary actions is a defining human characteristic. A widely accepted definition characterises voluntary actions as being internally generated; specified by a person's decisions and intentions rather than by external stimuli. An important aspect of voluntary action is the decision not to act. This decision can take two forms. First, one might decide not to begin any action preparation at all, but remain in an inactive state. Second, one might prepare an action, but subsequently make a deliberate decision to inhibit the execution of the action. Respectively, these have been called 
"early" and "late" decisions about whether to act (Haggard, 2008). Here we concentrate on the second "late" form, involving the decision to inhibit an action for which the neural preparation has already begun. Such internal inhibition could prevent us from inappropriately and automatically reacting to environmental stimuli, for example when suppressing the urge to utter an inappropriate remark that may arrive uninvited on the tip of our tongue in a social situation. Concepts of action responsibility point out that we are responsible for our actions because we could have decided to withhold them (Dennett, 1984). Inhibition has also played a key role in recent debates about the nature of volition. Materialist neuroscience holds that conscious intention ("urge") is a consequence of unconscious preparatory brain activity. Libet (1999) suggested that conscious will may nevertheless influence our actions through a second mechanism of "conscious veto" occurring between the awareness of intention and the onset of movement. This view replaces free will with "free won't” (Obhi \& Haggard, 2004). However, the theoretical objections to conscious causation that apply to the case of free will apply equally to "free won't".

Here we set aside philosophical considerations, and consider the process of intentional inhibition itself. The experience of deciding to withhold an action at the last moment is recognised by many people. However, experiental studies of last-moment inhibitory control generally involve external stop signals, rather than internal decisions (e.g. De Jong, Coles, \& Logan, 1995; Logan, Cowan \& Davis, 1984). In these paradigms, participants respond to 'Go' stimuli but are required to inhibit their response if a 'NoGo' or 'stop-' signal is delivered. These studies suggest a specific cognitive function of externally-driven inhibition, localised to right inferior frontal cortex (Verbruggen \& Logan, 2008; Aron, Fletcher, Bullmore, Sahakian, \& Robbins, 2003; Aron \& Poldrack, 2006; Chambers, Bellgrove, Stokes, Henderson, Garavan, Robertson, \& Mattingley, 2006).

Intentional inhibition involves an internal decision to stop at the last moment, rather than a response to an external stop-signal. Although this form of inhibition is clearly relevant to responsibility for action, it has been largely ignored in the experimental literature, 
perhaps because it is hard to study. In particular, an intentional action that is intentionally inhibited has no imperative stimulus, and no behavioural output. Therefore, there is no overt marker for the neural processes being studied. Recently, Brass and Haggard (2007) developed a method of studying intentional inhibition based on subjective markers. Participants freely decided when to press a key, but were also instructed to withhold the keypress at the last possible moment on some trials. That is, they were instructed to reproduce on every trial the decision process between action and inhibition that we recognise from key moments of everyday life. Using Libet's clock method, participants reported the exact moment when they experienced the urge to press the key (Libet's “W judgement”) even on trials where they inhibited the overt movement itself. Thus, the subjective experience of conscious intention provided a temporal marker for comparing fMRI activations on trials where participants prepared but then intentionally inhibited actions to those on trials where they prepared and then executed actions. Intentional inhibition was specifically associated with activation of an area of left fronto-median cortex. Although these conclusions, and the present paper, depend on Libet et al.'s (1983) method, they do not require all the assumptions about the source of voluntary action that characterise the 'free will' debate. Specifically, the experimental logic requires only that people have temporally-specific conscious experiences during the generation of endogenous actions, that these experiences are related to specific brain processes, and that the experience and the brain process occur after the onset of action preparation, but prior to a 'point of no return' for action execution.

However, the poor temporal resolution of fMRI means that such methods cannot clearly identify when the putative inhibitory processes occurred. Indeed, timing is crucial to identifying the process at all: the last-moment intentional inhibition of interest here should occur after action preparation but before execution. Timing information is required to distinguish inhibition from other related events, such as the feeling of frustration (Abler, Walter \& Erk, 2005) associated with failing to complete actions.

EEG, in contrast, has excellent temporal resolution. It has been used extensively to investigate both action preparation processes (Pfurtscheller, 1992), and external stop- 
signal inhibition (De Jong, Coles \& Logan, 1995). Few previous studies have investigated the EEG correlates of intentional inhibition, but Hummel and colleagues (Hummel, Andres, Altenmüller, Dichgans, \& Gerloff, 2002) observed focal increases of oscillatory alpha activity over sensorimotor areas when a novel task context required participants to tonically inhibit previously acquired sensorimotor associations. Serrien and colleagues reported increased coherence between frontal and motor cortices during voluntary suppression of motor tics in patients with Tourette’s syndrome (Serrien, Orth, Evans, Lees, \& Brown, 2005).

Here, we used EEG frequency analysis to investigate the processes of intentional inhibition when participants were instructed to prepare and then cancel a voluntary action. A subjective marker ( $\mathrm{W}$ judgement) was used to align recordings. Because W judgements are quite variable, the chances of detecting any event-related potential (ERPs) corresponding to inhibition could be low. However, event-related changes in EEG spectral power may occur over longer time scales than many ERPs, and have a better signal-to-noise ratio (Pfurtscheller, 1992). Event-related desynchronization (ERD) of upper alpha- and lower beta-band rhythms (8-24 Hz) is associated with motor preparation and execution. Movement termination is followed by an increased synchronization (ERS; Pfurtscheller \& da Silva, 1999), or post-movement "beta rebound", presumably reflecting the resetting of cortical motor networks. Therefore, we have used sensorimotor oscillations, rather than event-related potentials, to investigate the intentional inhibition of voluntary actions.

\section{Methods}

\subsection{Participants}

A total of 16 participants gave their informed consent to take part in this study, with UCL ethical committee approval. One participant showed excessive blinking, and one was unable to perform the time-judgement task. The remaining 14 participants (eight 
females) included in the analysis were all right-handed, and had a mean age of 23.9 $(\mathrm{SD}=5.9)$ years.

\subsection{Procedure}

The experiment consisted of 7 blocks of 40 trials each. There were two experimental conditions; "action only" and "act or inhibit". An initial practice block and the first two experimental blocks were action only blocks. After a short rest, participants then performed 4 act or inhibit blocks. This design ensured that comparisons of movement trials in each condition were based on similar numbers of trials. A fixed order of conditions was used, because of the possibility that inhibition has strong and enduring effects on action-related processes. By having action only blocks first in the experiment, prior to any instruction to inhibit, we obtained a pure estimate of action-related processing.

\subsection{Procedure for the 'action only' blocks}

Participants sat in front of a screen and watched a clock-hand of radius $1.3 \mathrm{~cm}$ rotating every $5120 \mathrm{~ms}$. They were asked to prepare and execute voluntary keypress actions with their right index finger at a time of their own choosing, but within the first revolution of the clock (see Supplementary Material S1.1 for full task instructions). They were not to pre-decide the time of the keypress action, or respond to salient clock positions. The clock-hand stopped at a random delay after the action. Participants then reported as accurately as possible, where the clock-hand was when they first felt the intention to press the key.

\subsection{Procedure for the 'act or inhibit' blocks}

In act or inhibit blocks, participants planned actions on every trial as before. However, they were instructed to cancel the action at the last possible moment on some trials that they freely selected (see Supplementary Material S1.2). Participants were 
instructed not to decide in advance whether they would act or not, but to try to make that decision at the last possible moment, after preparing the keypress action. On trials where participants did not press the button, the clock-hand stopped rotating at a short random delay after the first complete revolution of the clock-hand. Participants were encouraged to try and make approximately $50 \%$ actions and $50 \%$ cancellations. They were not instructed to 'behave randomly'.

\subsection{EEG recording and analysis}

EEG data were recorded with $\mathrm{Ag} / \mathrm{AgCl}$ electrodes from sites F3, Fz, F4, FC3, $\mathrm{FCz}, \mathrm{FC} 4, \mathrm{C} 3, \mathrm{Cz}, \mathrm{C} 4, \mathrm{P} 3, \mathrm{Pz}, \mathrm{P} 4, \mathrm{O} 1$ and O2. EEG was recorded with reference to electrode AFz. Electro-oculogram (EOG) was recorded by placing Ag/AgCl electrodes to the supra- and sub-orbit of the right eye and on the external canthi of each eye. Electrode impedance was kept below $5 \mathrm{k} \Omega$. EEG was sampled at $500 \mathrm{~Hz}$, bandpass filtered between 0.1 and $250 \mathrm{~Hz}$, and re-referenced to linked mastoid electrodes. Eye movement artefacts were eliminated by rejecting epochs containing signals greater than $+120 \mu \mathrm{V}$ or less than $-120 \mu \mathrm{V}$ from the vertical EOG electrodes; $12.8 \%$ of epochs were thereby rejected. Further visual inspection confirmed that the remaining epochs were artefact-free.

\subsection{ERD / ERS Computation}

EEG data were collected into event-locked epochs, extending from $1000 \mathrm{~ms}$ before each event to $500 \mathrm{~ms}$ after, and averaged. Unless otherwise stated, the event used for time-locking action trials was the moment of the participant's keypress, while the event used for time-locking inhibition trials was the participant's reported time of conscious intention (W judgement). Event-related power spectra were calculated for each epoch, the power during a baseline interval from -1000 to $-800 \mathrm{~ms}$ prior to the locking event was subtracted from the power at each time-point, and the epochs averaged. ERD / ERS was defined as a decreased or increased power relative to baseline in the classic sensorimotor rhythm bands (8-24 Hz; Pfurtscheller \& da Silva, 1999). 
We used SPM5 software (Wellcome Department of Imaging Neuroscience, London, UK) to allow statistical inferences in time-frequency space (Kilner, Kiebel \& Friston, 2005). This method uses Random Field Theory to adjust p-values from statistical parametric maps (SPMs) of time-frequency data. These maps were then smoothed by convolution with a Gaussian kernel in both time [12 ms, FWHM (full-width at half-maximum) and frequency (2 Hz, FWHM; see Figures 1-3). P-values were adjusted for multiple comparisons across all time-frequency points analysed ("resolution elements" or "resels"; see Kilner, Kiebel \& Friston; 2005). The method makes no predictions about the time or frequency locations of possible effects, and is appropriate since the timing of intentional inhibition processes is not precisely known a priori. Our

method assumes only that the relevant neural activity occurs within the frequency bands characterised by sensorimotor rhythms, and within a time window centred on reports of conscious intention, and extending to the expected time of physical movement. Alpha levels for all analyses were set at 0.05 .

\section{Results}

\subsection{Behavioural and perceptual results}

The mean proportion of inhibition trials was $49.7 \%$ (similar to Brass \& Haggard, 2007; $45.5 \%$ ); there were some inter-individual differences with the proportion of inhibition trials ranging from 41.2 to $60.4 \%$. We investigated the sequential pattern of action / inhibition in each participant's data. The average number of runs, defined as trials whose outcome differed from the previous trial (Wald, \& Wolfowitz, 1940), was 94 $(\mathrm{SD}=13)$. This number is more than what would be expected if a purely random process generated an action / inhibition decision anew on every trial [mean number of runs $=80$; $(\mathrm{SD}=6)$, based on an average score from a series of 100 computer-generated random sequences]. Our result is consistent with the random number generation literature that shows when producing random numbers or manual responses, people typically deviate 
systematically from statistical randomness and exhibit biases such as avoiding repetition of the previous response (Brown, Soliveri, \& Jahanshahi, 1998; Ginsburg, \& Karpiuk, 1994). On trials where a movement was made, participants reported the subjective experience of deciding to initiate an action later, and therefore closer to the keypress time, in the action only blocks [mean $=-283 \mathrm{~ms}(\mathrm{SD}=164)$ ] than in the act or inhibit blocks [mean $=-408 \mathrm{~ms}(\mathrm{SD}=415)]$. This difference was significant $\mathrm{t}(13)=2.846$; $\mathrm{p}=0.014$.

\subsection{ERD / ERS results}

Grand average topographic maps for induced spectral activity in action trials in both the action only and act or inhibit conditions, locked to the time of the keypress, are shown in Figure 1. Alpha and lower beta event-related desynchronization (around 9-14 $\mathrm{Hz}$ ) developed bilaterally over central electrodes before action onset (see Figure 1a and b). This pattern replicates several previous studies showing beta-band event-related desynchronization (ERD) during action preparation and execution (e.g. Pfurtscheller \& da Silva, 1999; Kristeva-Feige, Feige, Makeig, Ross, \& Elbert, 1993). Inspection of electrode C3 in the action only condition (Figure 1a), shows event-related desynchronization beginning 374 ms before keypress and centred on a frequency of 10.5 Hz. This frequency value is similar to that found by Neuper and Pfurtscheller (2001), though the ERD onset is later in our data. At the same electrode, a post-movement ERS (beta rebound; Figure 1a) began $246 \mathrm{~ms}$ after keypress and peaked at $24.8 \mathrm{~Hz}$ (Neuper and Pfurscheller (2001).

\section{FIGURE 1 ABOUT HERE}

Inhibition trials in the act or inhibit condition were analysed time-locked to the judgement of conscious intention (W). The grand average (Figure 2) did not show the beta-ERD characteristic of action trials. Instead, they showed a peak in event-related synchronization around the time of conscious intention. This peak was stronger and more 
distinct frontally and over the left hemisphere, notably at electrode site FC3. We used statistical parametric mapping (SPM; Friston, Ashburner, Kiebel, Nichols, \& Penny, 2007) to investigate whether this neural correlate of inhibition was significant. We predicted that the neural correlate of inhibition should occur in a broad time window around the $\mathrm{W}$ judgement, and in the broad spectral region associated with cognitivesensorimotor rhythms. We therefore defined a time window based on the typical W judgement across the entire experiment. Given a mean $\mathrm{W}$ judgement of -283 $\mathrm{ms}$ in action only blocks, and $-408 \mathrm{~ms}$ in act or inhibit blocks, we restricted our search for neural activity relative to intentional inhibition to a time period from $340 \mathrm{~ms}$ before to $340 \mathrm{~ms}$ after the $\mathrm{W}$ judgement. The frequency range of interest was 8 to $24 \mathrm{~Hz}$ (alphaand beta-bands), associated with movement-related ERD / ERS (Pfurtscheller \& Lopes da Silva, 1999).

\section{FIGURE 2 ABOUT HERE}

Using SPM, we statistically examined activity on all 9 electrodes over sensorimotor areas (F3, Fz, F4, FC3, FCz, FC4, C3, Cz, C4) in the inhibition trials. This analysis investigated whether there were any increases / decreases in spectral power, relative to the baseline period, that were statistically significant at the group level, without making any priori assumptions about where in the time-frequency region of interest these might be found. The results are shown in Table 1. Correcting for multiple comparisons at the cluster level showed a significant increase in beta-band power (betaERS) over the left frontal area at site FC3. Beta-ERS at electrode FC3 was significant at the cluster-level $(\mathrm{p}=0.022)$ and also survived comparison corrected at the resel-level for family-wise error ( $\mathrm{p}=0.026$ ). The peak in beta-ERS at FC3 was found at $14.0 \mathrm{~Hz}$, and 12 ms before the $\mathrm{W}$ judgement. Because SPM defines the cluster only at the group level, no statistically meaningful measure of inter-individual variability is possible. In addition, a second, later peak in ERS was found at electrode F3 at $11.9 \mathrm{~Hz}$, and $342 \mathrm{~ms}$ after the time of participants' mean W judgement (cluster-level, $\mathrm{p}=0.047$; resel-level corrected for family-wise error, $\mathrm{p}=0.038$ ). Since the $\mathrm{W}$ judgement for action trials in the act or inhibit 
block occurred on average $408 \mathrm{~ms}$ prior to keypress, this second peak occurred just before the time when the action might have taken place had it not been inhibited.

\section{INSERT TABLE 1 ABOUT HERE}

Our interest focused on the earlier peak in beta-ERS at FC3, since its timing made it a more plausible correlate of intentional inhibition. To compare this activity across conditions, we first re-computed the spectral power in action trials from the act or inhibit and action only conditions relative to the $\mathrm{W}$ time, rather than keypress onset, so that inhibition and action data had a common time reference. Figure 3 compares the grand average FC3 spectral power for inhibition trials and action trials in the act or inhibit condition for the time-frequency window of interest. Note that the peak ERS in the grand average data shown in Figure 3b occurred slightly after conscious intention. Nevertheless the peak of the cluster in the SPM statistical map occurred $12 \mathrm{~ms}$ before conscious intention (see Supplementary Material; Figure S1), because the ERS at that time was more consistent across participants, although of lower magnitude.

\section{FIGURE 3 ABOUT HERE}

W-locked spectra for action trials in the act or inhibit condition were strongly similar to those in the action only condition (Figure 1). We measured the spectral power at FC3 in each action condition at the time-frequency corresponding to the inhibitionrelated activity in Figure 3b (12 ms prior to conscious intention, $14 \mathrm{~Hz}$ ). There was no difference in spectral power between these conditions at the time-frequency point of interest [t(13)=0.967; $\mathrm{p}=0.351]$, and they were therefore averaged. Next, we used a planned comparison to compare the neural activity between inhibition and the averaged action trials. Because ERD is the accepted neural correlate of movement, we predicted higher power (relative ERS) on inhibition trials compared to action trials, and a one-tailed test was therefore appropriate. We found statistically higher power in inhibition trials than at the same time and frequency in action trials; $\mathrm{t}(13)=2.536 ; \mathrm{p}=0.012$ (one-tailed). 
Finally, to investigate if inhibition-related ERS might be systematically related to features of EEG activity preceding the conscious intent to press, we statistically compared activity locked to the time of the keypress for all 9 electrodes in action trials in both the action only and act or inhibit conditions (Figure 1a and b). Our interest was whether differences in activity early on in the epoch shown in Figure 1 might explain the ERS seen in Figure 3b. There were some significant differences between early activity in the action only and act or inhibit conditions. The most consistent was a stronger ERS for action only trials compared to act or inhibit trials. This was seen over F3, FC3, FC4 and C3 electrodes, peaking on average $697 \mathrm{~ms}(\mathrm{SD}=73)$ before keypress, at $5.3 \mathrm{~Hz}(\mathrm{SD}=1.5)$. This early difference is difficult to interpret conclusively, but it is clearly distinct from the inhibition-related ERS seen in the inhibition trials (Figure 3b). Specifically, the early difference represents stronger ERS in trials where no inhibition could occur (Figure 1a) than where it could occur (Figure 1b). In contrast, Figure 3b shows ERS for inhibition trials but not for action trials, which is clearly left-lateralised. We found no statistical evidence for the reverse contrast, of stronger ERS in act or inhibit trials than in action only trials for any electrode at the cluster-level $(0.173>\mathrm{p}<1.000)$. Moreover, the timing of the effects is clearly different: the early difference between Figures 1a and $1 \mathrm{~b}$ peaked $697 \mathrm{~ms}$ before the keypress, while the ERS of Figure 3b peaked $12 \mathrm{~ms}$ before the conscious intention to act. Since conscious intention occurred $408 \mathrm{~ms}$ before keypress on action trials, this would imply a separation of $277 \mathrm{~ms}$ (=697-408-12 ms) between the two peaks. Beta-ERS at electrode FC3 (Figure 3b) seems to reflect genuine inhibitionspecific activity, rather than a continuation of some other, confounding difference between action only and act or inhibit conditions.

\section{Discussion}

Like previous studies, we found that participants could report an experience of intention, occurring some hundreds of milliseconds prior to voluntary actions (Libet, Gleason, Wright, \& Pearl, 1983; Sirigu, Daprati, Ciancia, Giraux, Nighoghossian, Posada, \& Haggard, 2004). Moreover, participants were able to report this experience even on trials 
where they were instructed to prepare the action but then inhibit it at the last possible moment (Brass \& Haggard, 2007). We further found that the perceived time of intention (W judgement) in action trials was earlier in blocks where participants had the possibility of inhibiting each action than in pure action blocks where they never inhibited. This difference is consistent with an additional time-consuming decision whether to proceed with the action or inhibit it, occurring after the moment of conscious intention, but prior to action execution. Alternatively, the possibility of inhibiting might boost attention to intention (Lau, Rogers, Haggard, \& Passingham, 2004), thus lowering the threshold level of activity at which participants experience W (cf. Matsuhashi \& Hallett, 2008). This possibility is consistent with an increase in effective connectivity between fronto-median cortex and pre-SMA during intentional inhibition (Kühn, Haggard, \& Brass, 2008). Finally, differences in W judgements between action only and act or inhibit blocks could reflect an earlier, stronger process of neural preparatory activity in the latter.

Our EEG results clarify the neural basis of intentional inhibition. Brass and Haggard (2007) previously demonstrated that intentional inhibition involves the left fronto-median cortex (FMC), and also the left insula. However, fMRI could not reveal the time-course of these activations. The time-course is critical to defend the concept of true intentional inhibition, in the sense of a final predictive check before action, from sceptical attack (Haggard, 2008). Because inhibition produces no behavioural output, a participant who did not heed the task instruction, but simply let their mind wander, could appear to have performed a successful inhibition trial. A sceptic might hypothesise that Brass and Haggard's (2007) FMC activation corresponded to mind-wandering, boredom, or retrospective random-number generation, rather than true intentional inhibition. The present study, however, shows that intentional inhibition has a reliable neural correlate with a plausible time-course. Had participants done nothing at all on inhibition trials, and merely confabulated a time of conscious experience to satisfy the experimenter's question at the end of the trial, one would not predict a consistent pattern of induced EEG activity locked to the $\mathrm{W}$ judgement.. 
The timing and localisation of this neural activity deserve special consideration. The first beta-ERS occurred some $12 \mathrm{~ms}$ before the $\mathrm{W}$ judgement. This represents the broad time interval between the preparation of an action and the time that action might be expected to occur had it not been inhibited. This corresponds to some $358 \mathrm{~ms}$ before mean predicted action execution, because the peak ERS occurred $12 \mathrm{~ms}$ before the mean time of $\mathrm{W}$ judgement, and mean $\mathrm{W}$ averaged $346 \mathrm{~ms}$ before the keypress (average of 283 $\mathrm{ms}$ in the action only and $408 \mathrm{~ms}$ in the act or inhibit blocks; see Section 3.1). The timing of this neural activity is relatively late in the preparation of voluntary action, and possibly after action preparation has reached the stage of specifying specific motor parameters for executing an action (Haggard \& Eimer, 1999; Pacherie, 2008).

Does the FC3 ERS correspond to the decision to inhibit itself, or some other factor associated with inhibition? For example, it could reflect a heightened attention to volition (Lau, Rogers, Haggard, \& Passingham, 2004) due to conflicts between alternative possibilities of action or inhibition (Nachev, Rees, Parton, Kennard, \& Husain, 2005), or increased self-monitoring. Braver, Barch, Gray, Molfese, \& Snyder (2001) found that the inhibition of a prepared response results in a similar degree of anterior cingulate cortex (ACC) activation as the execution of the response. Conflict and monitoring should occur equally in both inhibition trials and action trials, but seemed absent from action trials (Figure 3a). Alternatively, FC3 ERS could be the result of a decision made much earlier, perhaps at the start of each trial. In fact, we instructed participants to decide at the last possible moment. However, an explanation based on pre-decision is hard to rule out: people often make decisions but implement them later, and this strategy works well (Bargh, Gollwitzer, Lee-Chai, Barndollar, \& Troetschel, 2001). In principle, the FC3 ERS could represent the mere expression of this earlier decision, rather than the decision itself. However, a number of arguments disfavour the pre-decision hypothesis. First, if people pre-decided to inhibit, they might not prepare the action in the normal way, but perhaps merely simulate it. We found no differences between action and inhibition trials during the initial phases of movement preparation. Second, our temporal judgement results are consistent with a time-consuming decision process intervening between intention and action when participants were asked to decide 
whether to inhibit or not. Third, in another study of intentional inhibition (Kühn \& Brass, 2009), participants performed a stop-signal task but were also occasionally presented with a signal instructing them to freely decide whether to act or not, as in the present study. At the end of each "decide" trial, participants reported whether they had decided to act, decided to inhibit, or had not yet decided between these alternatives (the last option is a possible alternative explanation of absence of any response). That study found a relatively high frequency of 'not yet decided' responses, suggesting first that people do not always pre-decide between action and inhibition, and second that they can distinguish having decided from not having decided by introspection alone.

In summary, our results identify the neural correlate of a form of inhibition which intervenes in the progression between preparation and execution of voluntary actions. This 'last-moment' inhibition should be distinguished from more tonic forms of inhibition, such as instructed withholding of a previously learned action for an extended period of time (Erbil, \& Ungan, 2007; Hummel, Andres, Altenmüller, Dichgans, \& Gerloff, 2002). Previously, Alegre and colleagues (Alegre, Gurtubay, Labarga, Iriarte, Valencia, \& Artieda, 2004) reported beta-band oscillatory activity related to motor preparation and inhibition in a Go/NoGo paradigm. They observed the expected alphaand beta-band desynchronization after Go signals, followed later by beta rebound. Interestingly, NoGo signals elicited beta synchronization with a left fronto-central topography similar to ours (see their Figure 4b). Our results may be an internallygenerated counterpart of their NoGo ERS. Future research might profitably compare intentional and external inhibition in the same participants.

Our method does not quantify the duration of the inhibition-related activity, but the grand average data suggest a duration of 100-200 ms (see Figure 2; electrode FC3). Moreover, the cluster containing the peak tends to merge with a later cluster extending to at least $340 \mathrm{~ms}$ post $\mathrm{W}$. This second peak was statistically significant at electrode F3 (Figure 2). Broadly, this timing is consistent with a process of intentional inhibition beginning relatively late in neuromotor preparation, and continuing for several hundred milliseconds up until the time where action execution might originally have been 
predicted. Intentional inhibition appears to be a time-consuming process (Walsh \& Haggard, 2007) rather than a sudden internal signal or switch (De Jong, Coles \& Logan, 1995; Coxon, Stinear \& Byblow, 2007).

Finally, the beta-ERS associated with intentional inhibition was most prominent at frontal electrodes. Previously, Brass and Haggard (2007) observed a frontal midline activation using an almost identical paradigm in fMRI. Our beta-ERS could arise from the same region of cortex, which they identified as BA9. However, our data showed stronger betaERS in the left hemisphere. Interestingly, this left lateralisation of intentional inhibition contrasts with exogenous inhibition triggered by external stop-signals, which consistently has a right frontal focus (Aron, Robbins \& Poldrack, 2004), according to both fMRI (Aron \& Poldrack, 2006) and lesion studies (Aron, Fletcher, Bullmore, Sahakian, \& Robbins, 2003). The pre-SMA has also been associated with the balance between action and inhibition on the basis of both neuropsychological deficits (Della Sala, Marchetti, \& Spinnler, 1991; Sumner, Nachev, Morris, Peters, Jackson, Kennard, \& Husain, 2007) and fMRI activations (Nachev, Rees, Parton, Kennard, \& Husain, 2005). We have not performed any source localisation, so cannot draw any strong conclusions about preSMA involvement. However, we note that fMRI activations of the pre-SMA are often confined quite strictly to the midline, in contrast to the clear left-lateralisation we observed in EEG.

Could our inhibition-related ERS be a form of post-movement beta rebound? Beta rebound is thought to reflect the deactivation or "idling" of motor cortical networks (Pfurtscheller, 2001), or the resetting of previously activated motor networks (Pfurtscheller, Woertz, Supp, \& Lopes da Silva, 2003). Beta rebound is also present after motor imagery and median nerve stimulation (Neuper \& Pfurtscheller, 2001). However, beta rebound lasts for approximately $2 \mathrm{~s}$, with the peak in its oscillatory power occurring approximately $1 \mathrm{~s}$ after the end of motor tasks (Pfurtscheller, Neuper, Brunner, \& Lopes da Silva, 2005). In contrast, the beta synchronization observed on inhibition trials in the present study was focused fronto-centrally and was relatively short-lived, lasting for approximately $200 \mathrm{~ms}$ (see Figure 3b). Moreover, our ERS occurred well before the time 
that action might be expected to occur had it not been inhibited. Thus, the spatiotemporal characteristics of ERS on inhibition trials are not consistent with post-movement beta rebound. Instead, this ERS may reflect an "active inhibition" (Pfurtscheller \& Neuper, 1997) of neural circuits involved in the preparation for action. The effective connectivity between fronto-median cortex and pre-SMA during intentional inhibition (Kühn, Haggard, \& Brass, 2008) could be a mechanism for this process.

Our findings are relevant to a number of neurological and psychiatric conditions. We suggest that the process of intentional inhibition may be inversely related to impulsivity. Impulsive behaviour, and particularly impulsive-aggressive behaviour, is related to a range of psychiatric conditions linked to hypofrontality, and also to criminality e.g. substance abuse, drunk driving, gang membership, and the use of violence (Bechara \& Van Der Linden, 2005; Houston \& Stanford, 2005; Raine, 2002; Raine, Lencz, Bihrle, LaCasse, \& Colletti, 2000). Understanding the neural basis of intentional inhibition may be important in diagnosis and therapy for these disorders (Gao \& Raine, 2009). Further, an important part of human social development throughout childhood is learning to 'hold back' urges to action, often on the basis of cultural and educational instruction (Blakemore, 2008). Recent social psychological work in self-control also confirms the key role of intentional inhibition in complex task performance, and in human relations (Baumeister, Vohs, \& Tice, 2007; Tangney, Baumeister, \& Boone, 2004).

We recently proposed a model of voluntary action as a series of decisions: what to do, when to do it, and whether to perform the action at all [Brass \& Haggard, 2008; The What, When, Whether (WWW) Model of Intentional Action]. We think intentional inhibition may be linked to a final predictive check whether a planned action should be finally committed, or withheld. The underlying computations could be similar to those in continuous predictive forward models of motor adjustment (Miall \& Wolpert, 1996). There, the system state predicted from the current motor command is checked against the desired state. If the two states do not match, the motor command is adjusted. Crucially, this process can occur continuously, up until the moment of action execution. We suggest that the intentional inhibition of a discrete action may involve a similar process. 
Humans, and other primates, can, and often do prepare self-generated actions well in advance. However, circumstances may change during the long preparation time for voluntary action, and it may be worth checking whether the action is still desirable before the point of final commitment. A final predictive check allows a process of intentional inhibition before this point of no return. We suggest this sort of "late whether decision" (Haggard, 2008) is an essential adjunct of volition; intentional action without the capacity for intentional inhibition would be maladaptive. Here we have shown that intentional inhibition involves a specific neural process in left and midline frontal areas. This process seems to occur late in motor preparation. We used a subjective marker to identify the brain process of intentional inhibition in the absence of any behavioural output. In this sense, our data imply at least a loose association between conscious intention and intentional inhibition. However, the true causal relations between neuromotor preparation for action, intentional inhibition and conscious experience remain a topic for future research.

\section{Acknowledgements}

This research was supported by a Ghent University Special Research Fund (BOF) grant to MB and an ESRC grant RES-000-23-1571 to PH. Special thanks to James Kilner for help and advice with statistical parametric mapping (SPM). Also to Jason Musil for help with data collection.

\section{References}

Abler, B., Walter, H., \& Erk, S. (2005). Neural correlates of frustration. Neuroreport,16, 669-672.

Alegre, M., Gurtubay., I.G., Labarga., A., Iriarte, J., Valencia, \& M., Artieda, J. (2004). Frontal and central oscillatory changes related to different aspects of the motor process: a study in go/no-go paradigms. Experimental Brain Research, 159, 14-22. 
Aron, A.R., Fletcher, P.C., Bullmore, E.T., Sahakian B.J., \& Robbins T.W. (2003). Stopsignal inhibition disrupted by damage to right inferior frontal gyrus in humans. Nature Neuroscience, 6, 115-116.

Aron, A.R., \& Poldrack, R.A. (2006). Cortical and subcortical contributions to stop signal response inhibition: role of the subthalamic nucleus. Journal of Neuroscience, 26, 2424-2433.

Aron, A.R., Robbins, T.W., \& Poldrack, R.A. (2004). Inhibition and the right inferior frontal cortex. Trends in Cognitive Science, 8, 170-177.

Bargh, J.A., Gollwitzer, P.M., Lee-Chai, A.Y., Barndollar K., \& Troetschel, R. (2001). The automated will: Nonconscious activation and pursuit of behavioral goals. Journal of Personality and Social Psychology 81, 1014-1027.

Baumeister, R.F., Vohs, K.D., \& Tice, D.M. (2007). The strength model of self-control. Current Directions in Psychological Science, 16, 396-403.

Bechara, A., \& Van Der Linden, M. (2005). Decision-making and impulse control after frontal lobe injuries. Current Opinion in Neurology, 18, 734-739.

Blakemore, S-J. (2008). The social brain in adolescence. Nature Reviews Neuroscience, 9, 267-277.

Brass, M., \& Haggard, P. (2007). To do or not to do: the neural signature of self-control. Journal of Neuroscience, 27, 9141-9145.

Brass, M., \& Haggard, P. (2008). The What, When, Whether Model of Intentional Action. The Neuroscientist, 14, 319-325. 
Braver, T.S., Barch, D.M., Gray, J.R., Molfese, D.L., \& Snyder, A. (2001). Anterior cingulate cortex and response conflict: effects of frequency, inhibition and errors. Cerebral Cortex 11, 825-836.

Brown, R.G., Soliveri, P., \& Jahanshahi, M. (1998). Executive processes in Parkinson's disease - random number generation and response suppression. Neuropsychologia, 36, 1355-1362.

Chambers, C.D., Bellgrove, M.A., Stokes, M.G., Henderson, T.R., Garavan, H., Robertson I.H., \& Mattingley, J.B. (2006). Executive 'brake failure' following deactivation of human frontal lobe. Journal of Cognitive Neuroscience, 18, 444455.

Coxon, J.P., Stinear, C.M., \& Byblow, W.D. (2007). Selective inhibition of movement. Journal of Neurophysiology, 97, 2480-2489.

Della Sala, S., Marchetti, C. \& Spinnler, H. (1991). Right-sided anarchic (alien) hand: A longitudinal study. Neuropsychologia, 29, 1113-1127.

Dennett, D.C. (1984). Elbow Room: The Varieties of Free Will Worth Wanting. The MIT Press.

De Jong, R., Coles, M.G.H., \& Logan, G.D. (1995). Strategies and mechanisms in nonselective and selective inhibitory motor control. Journal of Experimental Psychology: Human Perception and Performance, 21, 498-511.

Erbil, N., \& Ungan, P. (2007). Changes in the alpha and beta amplitudes of the central EEG during the onset, continuation, and offset of long-duration repetitive hand movements. Brain Research, 1169, 44-56. 
Friston, K.J. Ashburner, J.T., Kiebel, S.J., Nichols, T.E. \& Penny, W.D. (2007). Statistical Parametric Mapping: The Analysis of Functional Brain Images. Elsevier Ltd.

Gao, Y., \& Raine, A. (2009). P3 event-related potential impairments in antisocial and psychopathic individuals: A meta-analysis. Biological Psychology, in press.

Ginsburg, N. \& Karpiuk, P. (1994). Random generation: analysis of responses. Perceptual and Motor Skills, 34, 357-358.

Haggard, P. (2008). Human volition: towards a neuroscience of will. Nature Reviews Neuroscience, 9, 934-946.

Haggard, P., \& Eimer, M. (1999). On the relation between brain potentials and the awareness of voluntary movements. Experimental Brain Research, 126, 128-133.

Houston, R.J., \& Stanford, M.S. (2005). Electrophysiological substrates of impulsiveness: potential effects on aggressive behavior. Progress in NeuroPsychopharmacology \& Biological Psychiatry, 29, 305- 313.

Hummel, F., Andres, F., Altenmüller, E., Dichgans, J., \& Gerloff, C. (2002). Inhibitory control of acquired motor programmes in the human brain. Brain, 125, 404-420.

Kilner, J.M., Kiebel, S.J., \& Friston, K.J. (2005). Applications of random field theory to electrophysiology. Neuroscience Letters, 374, 174-178.

Kristeva-Feige, R., Feige, B., Makeig, S., Ross, B., \& Elbert, T. (1993). Oscillatory brain activity during a motor task. Neuroreport, 4, 1291-1294.

Kühn, S. \& Brass, B. (2009). When doing nothing is an option: The neural correlates of deciding whether to act or not. NeuroImage, 46, 1187-1193. 
Kühn, S., Haggard, P., \& Brass, M. (2008). Intentional Inhibition: How the "Veto-Area” Exerts Control. Human Brain Mapping, 30, 2834 - 2843.

Lau, H.C., Rogers, R.D., Haggard, P., \& Passingham, R.E. (2004). Attention to Intention. Science, 303, 1208-1210.

Libet, B. (1999). Do We Have Free Will? Journal of Consciousness Studies, 6, 47-57.

Libet, B., Gleason, C.A., Wright, E.W., \& Pearl, D.K. (1983). Time of conscious intention to act in relation to onset of cerebral activity (readiness-potential). The unconscious initiation of a freely voluntary act. Brain, 106, 623-642.

Logan, G.D., Cowan, W.B., \& Davis, K.A. (1984). On the ability to inhibit simple and choice reaction time responses: a model and a method. Journal of Experimental Psychology: Human Perception and Performance, 10, 276-291.

Matsuhashi, M., \& Hallett, M. (2008). The timing of the conscious intention to move. European Journal of Neuroscience, 11, 2344-2351.

Miall, R.C., \& Wolpert, D.M. (1996). Forward models for physiological motor control. Neural Networks, 9, 1265-1279.

Nachev, P., Rees, G., Parton, A., Kennard, C., \& Husain, M. (2005). Volition and Conflict in Human Medial Frontal Cortex. Current Biology, 15, 122-128.

Neuper, C., \& Pfurtscheller, G. (2001). Event-related dynamics of cortical rhythms: frequency-specific features and functional correlates. International Journal of Psychophysiology, 43, 41-58. 
Obhi, S.S., \& Haggard, P. (2004). Free will and free won't. American Scientist, 92, 358365.

Pacherie, E. (2008). The phenomenology of action: A conceptual framework. Cognition, 107, 179-217.

Pfurtscheller, G. (1992). Event-related synchronization (ERS): an electrophysiological correlate of cortical areas at rest. Electroencephalography and Clinical Neurophysiology, 83, 62-69.

Pfurtscheller, G. (2001). Functional brain imaging based on ERD/ERS. Vision Research, 41, 1257-1260.

Pfurtscheller, G., \& da Silva, F.H. (1999). Event-related EEG/MEG synchronization and desynchronization: basic principles. Clinical Neurophysiology, 110, 1842-1857.

Pfurtscheller, G., \& Neuper, C. (1997). Motor imagery activates primary sensorimotor area in humans. Neuroscience Letters, 239, 65-68.

Pfurtscheller, G., Neuper, C., Brunner, C., \& Lopes da Silva, F. (2005). Beta rebound after different types of motor imagery in man. Neuroscience Letters, 378, 156-159.

Pfurtscheller, G., Woertz, M., Supp, G., \& Lopes da Silva, F.H. (2003). Early onset of post-movement beta electroencephalogram synchronization in the supplementary motor area during self-paced finger movement in man. Neuroscience Letters 339, 111-114.

Raine, A. (2002). Annotation: The role of prefrontal deficits, low autonomic arousal, and early health factors in the development of antisocial and aggressive behavior in children. Journal of Child Psychology \& Psychiatry, 43, 417-434. 
Raine, A., Lencz, T., Bihrle, S., LaCasse, L., \& Colletti, P. (2000). Reduced prefrontal gray matter volume and reduced autonomic activity in antisocial personality disorder. Archives of General Psychiatry, 57, 119-127.

Serrien, D.J., Orth, M., Evans, A.H., Lees, A.J. \& Brown, P. (2005). Motor inhibition in patients with Gilles de la Tourette syndrome: functional activation patterns as revealed by EEG coherence. Brain, 128, 116-125.

Sirigu, A., Daprati, E., Ciancia, S., Giraux, P., Nighoghossian, N., Posada, A., \& Haggard, P. (2004). Altered awareness of voluntary action after damage to the parietal cortex. Nature Neuroscience, 7, 80-84.

Sumner, P., Nachev, P., Morris, P., Peters, A.M., Jackson, S.R., Kennard, C., \& Husain, M. (2007). Human Medial Frontal Cortex Mediates Unconscious Inhibition of Voluntary Action. Neuron 54, 697-711.

Tangney, J.P., Baumeister, R.F., \& Boone, A.L. (2004). High Self-Control Predicts Good Adjustment, Less Pathology, Better Grades, and Interpersonal Success. Journal of Personality, 72, 271-324.

Touge, T., Werhahn, K.J., Rothwell, J.C., \& Marsden, C.D. (1995). Movement-related Cortical Potentials Preceding Repetitive and Random-Choice Hand Movements in Parkinson’s Disease. Annals of Neurology, 37, 791-799.

Verbruggen, F., \& Logan, G.D. (2008). Response inhibition in the stop-signal paradigm. Trends in Cognitive Sciences, 12, 418-424.

Wald, A., \& Wolfowitz, J. (1940). On a test whether two samples are from the same population. Annals of Mathematical Statistics, 11, 147-162. 
Walsh, E., \& Haggard, P. (2007). The internal structure of stopping as revealed by a sensory detection task. Experimental Brain Research, 183, 405-410. 
Figure 1. Topographic maps for action trials for the nine electrodes of interest over sensorimotor areas in the (a) action only and (b) act or inhibit conditions. Grand average spectral power data are locked to keypress (dashed vertical lines). Blue colour indicates event-related desynchronization (ERD), and red indicates event-related synchronization (ERS). Note ERD prior to and during movement, followed by ERS (beta rebound: BR) after movement (dotted rectangles, illustrative only; electrode C3). The mean time of the conscious intention to act (W judgement) +/- SD is indicated by the bar at the bottom of each figure. Note logarithmic ordinate.

Figure 2. Topographic maps for the nine electrodes of interest for inhibition trials in the act or inhibit condition. Grand average spectral power data are locked to the time of conscious intention (W judgement, dashed vertical lines). Colour conventions are as in Figure 1. Note ERS at electrode FC3 (14.0 Hz, $12 \mathrm{~ms}$ before $\mathrm{W}$, arrowed). Note logarithmic ordinate.

Figure 3. Grand average spectral power in the sensorimotor rhythm bands around the time of conscious intention (W judgement, dashed vertical line) for electrode FC3 in the act or inhibit condition for (a) action trials; the keypress occurred $408 \mathrm{~ms}(\mathrm{SD}=415 \mathrm{~ms}$ ) after the conscious intention to act (W), and (b) inhibition trials; the data are a subset of that shown in Figure 2. Alignment and colour conventions are as in Figure 1. Note logarithmic ordinate.

Table 1. Results table for inhibition trials in the act or inhibit condition from the analysis of the smoothed time-frequency statistical map (SPM), thresholded at $p<0.05$ uncorrected, and restricted to the $a$ priori window of interest (see Section 3.2) for the nine electrodes mounted over sensorimotor areas. The value of the peak resolution element ("resel") is shown. The time (ms) of peak activation is relative to the moment of conscious intention (W).

\begin{tabular}{ccccc}
\hline Channel & $\begin{array}{c}\text { Cluster-level } \\
\text { Corrected Probability }\end{array}$ & $\begin{array}{c}\text { Bin-level } \\
\text { Probability } \\
\text { Corrected for } \\
\text { Family-wise Error }\end{array}$ & $\begin{array}{c}\text { Cluster peak } \\
\text { Time (ms) }\end{array}$ & $\begin{array}{c}\text { Cluster peak } \\
\text { Frequency (Hz) }\end{array}$ \\
\hline F3 & 0.047 & 0.038 & 342 & 11.9 \\
Fz & 0.058 & 0.354 & 26 & 14.0 \\
F4 & 0.628 & 0.488 & 342 & 11.7 \\
FC3 & 0.022 & 0.026 & -12 & 14.0 \\
FCz & 0.057 & 0.384 & 16 & 14.2 \\
FC4 & 0.723 & 0.253 & -179 & 19.7 \\
$\mathbf{C 3}$ & 0.612 & 0.513 & -24 & 14.2 \\
$\mathbf{C z}$ & 0.565 & 0.472 & 342 & 11.9 \\
$\mathbf{C 4}$ & 0.871 & 0.803 & 342 & 18.0 \\
\hline
\end{tabular}


a) "Action only" condition
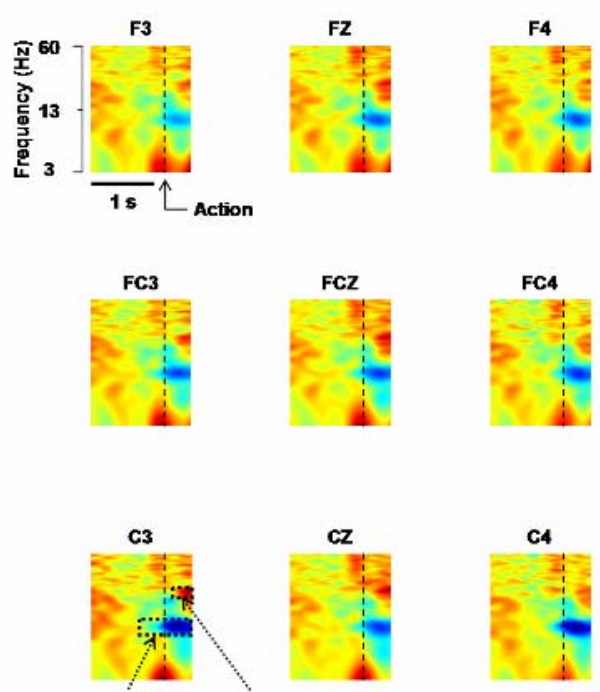

ERD
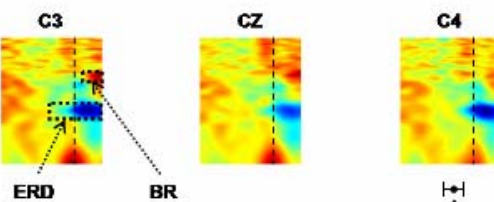

1.

Conscious b) Action trials in the "act or inhibie' condition
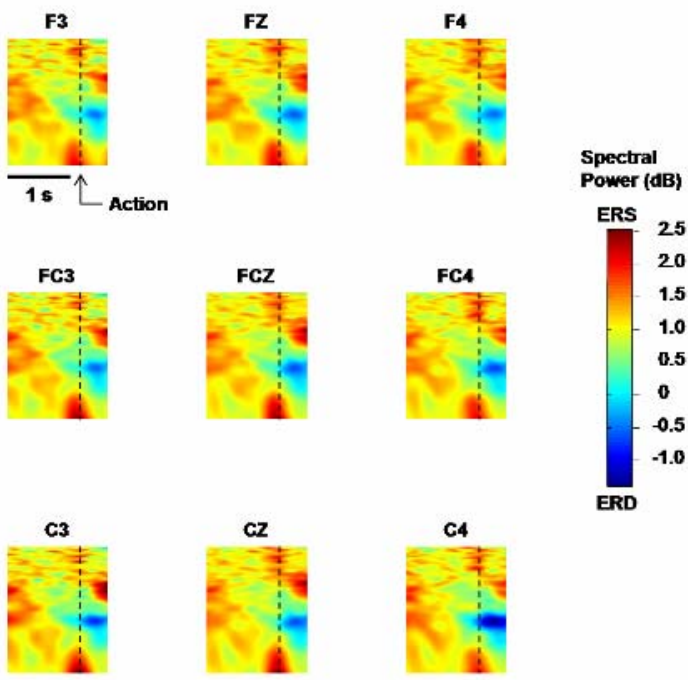

C4
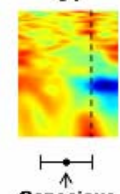

Conscious

Fig 1.

Inhibition trials in the "act or inhibit" condition

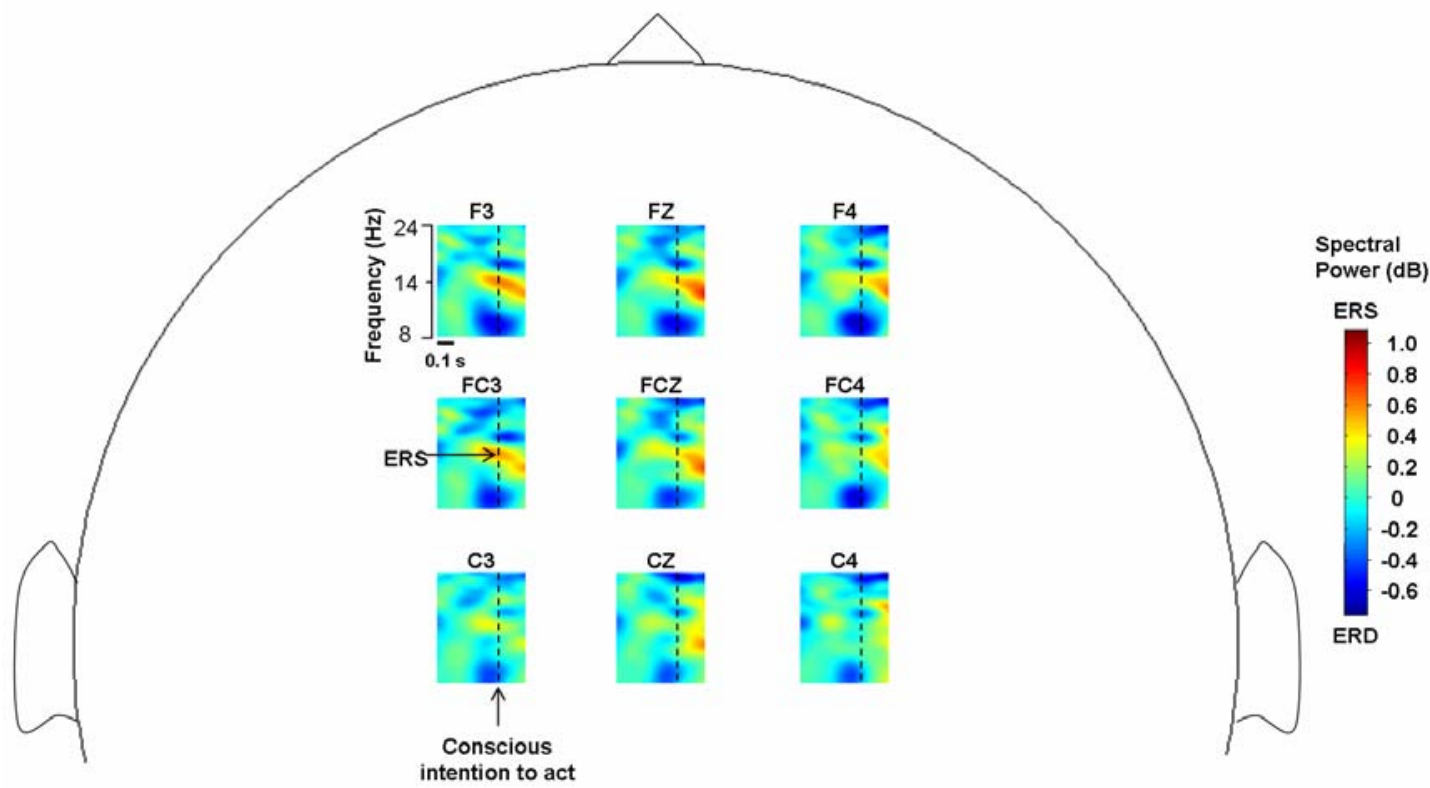

Fig 2. 
“Act or inhibif" condition
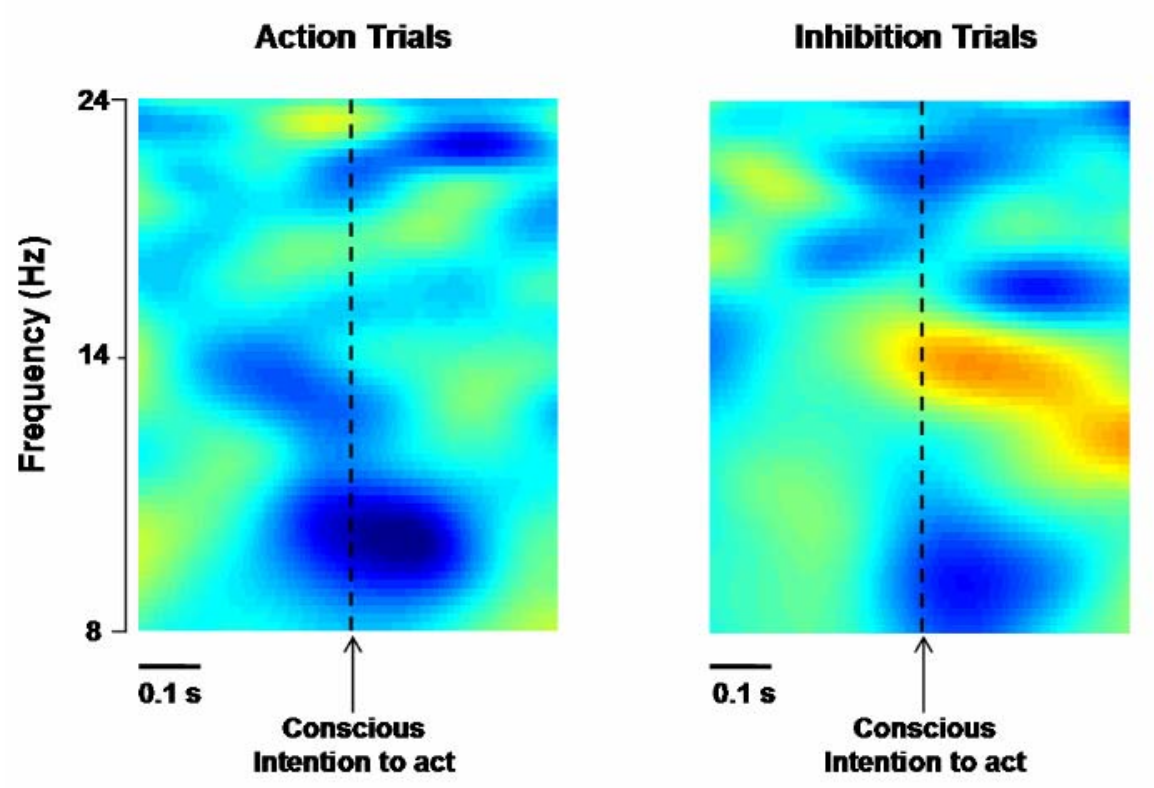

Spectral

Power (dB)

ERS

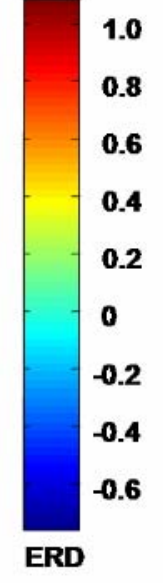

Fig 3. 